\title{
Seasonal and Interannual Variations of the Leeuwin Current off Western Aus- tralia from TOPEX/Poseidon Satellite Altimetry
}

\author{
Xiaoli Deng ${ }^{1, *}$, Cheinway Hwang ${ }^{2}$, Richard Coleman ${ }^{3}$, and Will E. Featherstone ${ }^{4}$ \\ ${ }^{1}$ School of Engineering and Centre for Climate Change Impact Management, The University of Newcastle, University Drive, \\ Callaghan, NSW 2308, Australia \\ 2 Department of Civil Engineering, National Chiao Tung University, Taiwan \\ ${ }^{3}$ Centre for Marine Science, University of Tasmania, Private Bag 78, Hobart, TAS 7001, Australia; CSIRO Marine and \\ Atmospheric Research, Hobart, Australia; Antarctic Climate and Ecosystems CRC, Hobart, Australia \\ ${ }^{4}$ Western Australian Centre for Geodesy and The Institute for Geoscience Research, Curtin University of Technology, GPO Box \\ U1987, Perth WA 6845, Australia
}

Received 15 November 2006, accepted 7 August 2007

\begin{abstract}
The Leeuwin Current (LC) is an eastern boundary current flowing strongly southwards along the Western Australian coastline. The current varies seasonally, with weaker southwards flow occurring during the austral summer (November to March), when southerly winds are strongest. Nearly 9.5 years of TOPEX/Poseidon-derived sea-surface heights, in conjunction with the AUSGeoid98 gravimetric geoid model, have been used to investigate the temporal characteristics of the LC over the area bounded by 20 to $45^{\circ} \mathrm{S}$ and 108 to $130^{\circ} \mathrm{E}$. The ocean dynamic height associated with the LC is used to compute the geostrophic parameters of volume transport, axis velocity, height jump, width, and axis locations of the current. These parameter estimates are then used to analyse the seasonal and interannual variability of the LC, as well as effects related to the El Niño Southern Oscillation (ENSO). Our results show that the LC is highly variable in terms of seasonal volume transport and is closely linked to ENSO events at interannual time-scales. Seasonally, when assuming an averaged isobath of $80 \mathrm{~m}$, the LC has maximum volume transport of up to $-7.2 \mathrm{~Sv}\left(10^{6} \mathrm{~m}^{3} \mathrm{~s}^{-1}\right.$, a negative sign means southwards transport $)$ in April - June and -8.4 Sv in May - August in regions west and south of Western Australia, respectively. Inter-annually, the LC has higher volume transports than the average transport during 1993 - 2003 in most La Niña years, and the opposite in most El Niño years, which is linked to inter-basin exchange between the Pacific and Indian Oceans.
\end{abstract}

Key words: TOPEX/Poseidon, Satellite altimetry, Leeuwin Current, Geostrophic parameters, ENSO, Ocean-surface currents, Western Australia

Citation: Deng, X., C. Hwang, R. Coleman, and W. E. Featherstone, 2008, Seasonal and interannual variations of the Leeuwin Current off Western Australia from TOPEX/Poseidon satellite altimetry. Terr. Atmos. Ocean. Sci., 19, 135-149, doi: 10.3319/TAO.2008.19.1-2.135(SA)

\section{INTRODUCTION}

The Leeuwin Current (LC) is a narrow ( $\sim 50 \mathrm{~km})$, long ( $5500 \mathrm{~km}$, Ridgway and Condie 2004), and meandering coastal current over the continental shelf slope offshore of Western Australia (WA) in the Southeast Indian Ocean (Fig. 1). It is geographically the analogue of the eastern boundary current. However, it flows poleward rather than equatorward as do other eastern boundary currents, such as the Benguela Current. The LC flows rapidly southward against the prevailing equatorward wind between North

\footnotetext{
* Corresponding author

E-mail:xiaoli.deng@newcastle.edu.au
}

West Cape $\left(22^{\circ} \mathrm{S}\right)$ and Cape Leeuwin $\left(35^{\circ} \mathrm{S}\right)$, then heads eastwards at Cape Leeuwin into the Great Australian Bight south of WA, and finally to the southern tip of Tasmania (e.g., Pearce 1991; Smith et al. 1991; Thompson 1984; Le Traon and Morrow 2001; Feng et al. 2003; Cresswell and Griffin 2004; Ridgway and Condie 2004). The strength of the LC varies throughout the year with strongest (weakest) southerly flow in the austral autumn and winter (spring and summer) when the opposing winds are weakest (strongest).

The LC's flow is highly variable in both space and time [a clear seasonal signal, with the El Niño Southern Oscillation (ENSO)-related variability] with typical surface 
current speeds of $\sim 50 \mathrm{~cm} \mathrm{~s}^{-1}$ but speeds of up to $1 \mathrm{~m} \mathrm{~s}^{-1}$ are common (e.g., Griffin et al. 2001; Cresswell and Griffin 2004). The LC spawns anti-cyclonic eddies of warm water and sometimes cyclonic eddies seaward of the current (e.g., Griffin et al. 2001; Morrow et al. 2003), and displays seasonal variations in volume transport and mesoscale variability (Smith et al. 1991; Morrow and Birol 1998; Feng et al. 2003), which plays an important role in the coupled ocean-atmosphere system. From Fig. 1, the ENSO-related interannual signals propagate poleward from northwest to west of WA's coast as coastally trapped waves (e.g., Clarke and Liu 1994; Feng et al. 2003). Therefore, it is important to understand the seasonal and interannual variability of the LC and its eddies because of their impacts on regional climate, marine ecosystems and fisheries (e.g., Godfrey and Ridgway 1985; Griffin et al. 2001; Le Traon and Morrow 2001; Domingues et al. 2006).

Previous studies of the LC (e.g., Cresswell 1991; Smith et al. 1991; Feng et al. 2003) have used in-situ data to understand the dominant driving mechanisms of the seasonal and interannual characteristics of the LC. In particular, Pariwono et al. (1986), Pearce (1991), Griffin et al. (2001), and Feng et al. (2003) found that the LC's interannual variability in sea-level is linked with ENSO phenomena. The sea-level west of WA is strongly influenced by the sea-level to the north in the western equatorial Pacific. The equatorial Rossby waves generated by remote zonal winds along the equator of the Indian and Pacific Oceans transmit high coastal sea levels during the La Niña years and low sealevels during the El Niño years (e.g., Pariwono et al. 1986; Griffin et al. 2001; Wijffels and Meyers 2004).

Since satellite radar altimetry has unique capabilities for producing global and synoptic sea-surface height (SSH) data coverage over the ocean surface, it can be used to observe the continental boundary currents (e.g., LeGrand 2005). Conventionally, oceanographic research uses sealevel anomaly (SLA) measurements rather than SSHs derived from satellite altimetry (e.g., Cresswell and Griffin 2004; Ridgway and Condie 2004). As the resolution and accuracy of currently available global geoid models are not adequate at mesoscale wavelengths (cf. Le Traon and Morrow 2001; LeGrand 2005), the SLA is obtained by subtracting a mean sea-surface (MSS), or an along-track mean profile, from the SSH. The MSS is derived from averaging altimeter-derived SSHs over a specified time period, typically several years or the entire duration of an altimetric mission.

In the LC region south of WA, the SLA maps from satellite altimetry and sea-surface temperature from satellite imagery have indicated the formation and evolution of the eddy field (Cresswell and Griffin 2004). The seasonal evolution of the boundary flow of the LC is also illustrated by a sequence of monthly maps of the SLA, from which the coastal sea level is depressed by $\sim 15 \mathrm{~cm}$

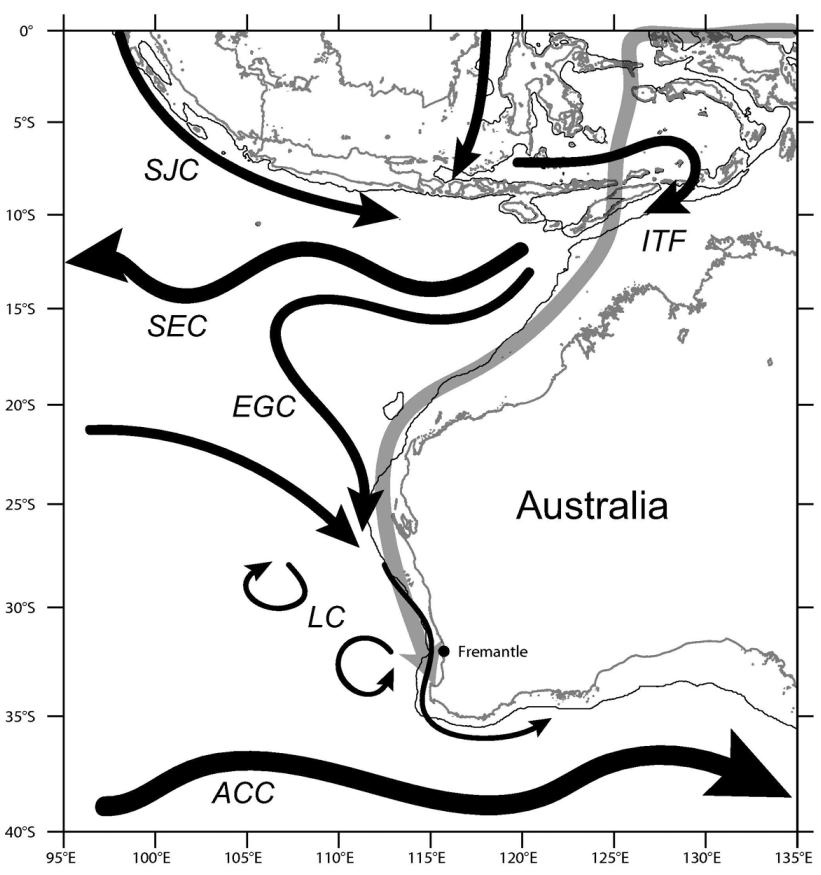

Fig. 1. Schematic of the major surface currents in the east-southeast Indian Ocean (adapted from Feng et al. 2003). ITF: Indonesian Throughflow; SEC: South Equatorial Current; SJC: South Java Current; EGC: East Gyral Current; LC: Leeuwin Current; ACC: Antarctic Circumpolar Current. The meandering of the SEC and the Leeuwin Current eddies are also sketched. A shaded, transparent arrow is used to highlight the waveguide along which the Pacific ENSO signals propagate.

in the regions west and south of WA's coast in summer and raised by about the same amount in winter (cf. Fig. 3 of Ridgway and Condie 2004).

In coastal regions where in-situ gravity data are available, another possible method to observe the ocean surface currents from satellite altimetry is to use the ocean dynamic height, which is the absolute sea surface height but uses the equipotential height of a gravimetric geoid model as a reference surface (e.g., LeGrand 2005). The regional estimates of the geoid are computed through the combination of existing global geoid models with in-situ gravity measurements (and altimetric data in some cases). Some previous studies (e.g., Tai 1990; Rapp and Smith 1994; Hwang 1996; Le Traon and Morrow 2001; Hwang and Kao 2002) have used a combination of a gravimetric geoid model and satellite altimeter-derived SSH data to evaluate the geostrophic parameters of the location, width, maximum velocity and surface transport of western boundary currents of the Gulf Stream and Kuroshio Current. From the altimeter-derived SSH and a regional geoid model, Haines et al. (2003) present a mean dynamic topography signal associated with the extension of the North Atlantic Current along the north-western coast of the United Kingdom (cf. Fig. 7 of Haines et al. 2003).

In the LC region, a $2^{\prime} \times 2^{\prime}$ AUSGeoid98 gravimetric geoid model $\left(40^{\circ} \mathrm{S}<\phi<8^{\circ} \mathrm{S}\right.$ and $\left.108^{\circ} \mathrm{E}<\lambda<160^{\circ} \mathrm{E}\right)$ ex- 
ists (Featherstone et al. 2001). AUSGeoid98 was computed using data from the EGM96 global geopotential model, the 1996 release of the Australian gravity database (including ship-track gravity measurements around Australia), a $9^{\prime \prime} \times 9^{\prime \prime}$ nationwide digital elevation model, and satellite altimeter-derived marine gravity anomalies. Comparisons of AUSGeoid98 with Global Positioning System (GPS and Australian Height Datum (AHD) heights across the continent indicate a root-mean-square (RMS) agreement of $\pm 0.36 \mathrm{~m}$ (Featherstone et al. 2001), though more recent estimates with newer GPS data indicate an RMS of $\pm 0.28 \mathrm{~m}$ (Featherstone and Sproule 2006). The half-wavelength of AUSGeoid98 is less than $5 \mathrm{~km}$, which is a suitable resolution for the investigation of the LC.

With the advent of significant improvement in terms of accuracy and resolution of global geoid models from GRACE (Gravity Recovery and Climate Experiment; Tapley et al. 2004), it is becoming possible to estimate ocean current characteristics with more certainty using the absolute ocean dynamic topography from gravimetric geoid models and satellite altimetry (cf. Tapley et al. 2003). Applications in coastal zones, however, still face challenges as the resolution of ocean currents is made more complicated by the proximity of the coastal boundaries, such as increased uncertainty in tide models and wet troposphere corrections.

Therefore, we investigate the seasonal and interannual variations in the geostrophic characteristics of the LC in the western and southern coastal regions of WA using TOPEX/Poseidon (T/P) altimeter data and AUSGeoid98. The sea-surface dynamic heights referenced to AUSGeoid98 are computed along $12 \mathrm{~T} / \mathrm{P}$ ground-tracks crossing the LC. The time-series of the LC's geostrophic parameters of axis location, axis velocity, width and volume transport are estimated and analysed. Analysis of the annual and interannual variations is also presented.

\section{STUDY AREA, DATA, AND METHODS}

\subsection{Study Area and Data}

The study area is focused on the LC system at the coastal margin stretching from the western $\left(108^{\circ} \mathrm{E}, 22^{\circ} \mathrm{S}\right.$; North West Cape) to soutern $\left(130^{\circ} \mathrm{E}, 45^{\circ} \mathrm{S}\right)$ coast of WA (Fig. 2). In the region from North West Cape to Cape Leeuwin $\left(115^{\circ} \mathrm{E}, 35^{\circ} \mathrm{S}\right)$, the coastal boundary is essentially meridional. Beyond Cape Leeuwin, the southern coast is aligned in a predominately zonal orientation. This is one of the very few extended meridional and zonal coastal boundaries found anywhere in the world (Ridgway and Condie 2004). Over most of the area, the continental shelf width (i.e., distance from the coast) varies between 50 and $100 \mathrm{~km}$, apart from the Great Australian Bight region (124 to $\left.135^{\circ} \mathrm{E}\right)$, where the shelf broadens to form a smooth plain (90 - $220 \mathrm{~km}$ wide) and with a very gentle slope (Ridgway and Condie 2004). The LC's core is typically at depths of $200 \mathrm{~m}$ and the cur- rent extends down to $\sim 250-300 \mathrm{~m}$ in depth. A northwards countercurrent (Leeuwin Undercurrent) is flowing beneath it.

The T/P data used are from cycles 11 (31 December 1992) to 364 (1 August 2002) of the standard Geophysical Data Records (GDRs) provided by AVISO (1996). It is well known that the altimeter lock is regained as the groundtrack goes from land (or water) to water (or land). This can affect the range measurements up to $\sim 28 \mathrm{~km}$ from the coastline (Deng and Featherstone 2006). To avoid this problem, the near-coastal data from the T/P GDRs are edited following the recommendation of Brooks et al. (1997). The method simply eliminates all data that have the Alt-Bad flag set, to ensure more reliable SSHs in the coastal region. This editing can be seen by the truncated ground-tracks near the coastline in Fig. 2.

The standard geophysical corrections provided by AVISO (1996) are applied to altimeter ranges. We used the TOPEX microwave radiometer (TMR) wet tropospheric correction, dry troposphere and ionosphere corrections, sea state bias, inverse barometer effect, elastic ocean tide from the CSR3.0 model (Eanes and Bettadpur 1995), and solid earth and pole tide corrections. Before computing the

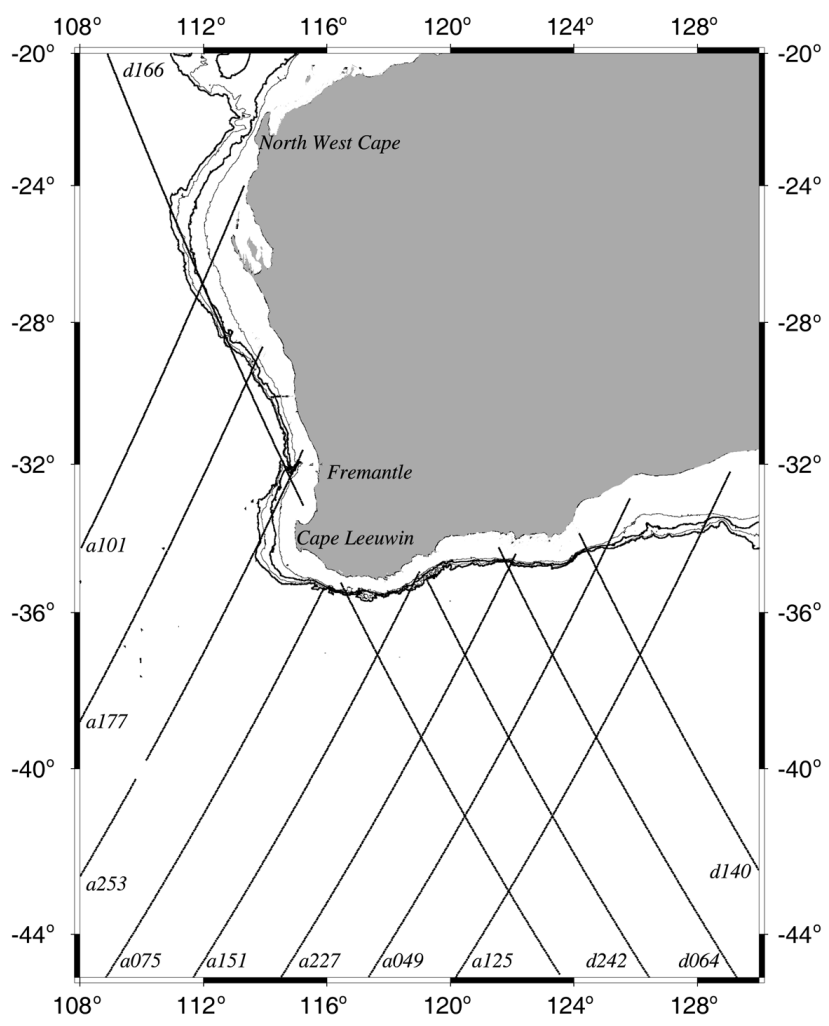

Fig. 2. Distribution of selected T/P tracks over the western and southern Australian coastal regions. The contours show the bathymetric depth from $500 \mathrm{~m}$ to $2000 \mathrm{~m}$ along the continental shelf edge. The affixes "a" and "d" before the track numbers denote an ascending and descending track, respectively. The satellite orbits from south to north along the ascending track and vice versa along the descending track. 
along-track ocean dynamic heights for each T/P track, the orbit that contained the most complete SSH data coverage amongst all cycles was chosen as a reference orbit for the track. The cross-track gradient correction was computed using the method of Wang and Rapp (1991) and the AUSGeoid98 model. This correction was then applied to SSHs to reduce them to the reference orbit. Finally, the along-track surface ocean dynamic heights were calculated by directly subtracting AUSGeoid98 geoid heights from the reference orbit SSHs.

Eight ascending and four descending T/P tracks were chosen (Fig. 2) because they cross the LC over the continental shelf edge at different locations. In this paper, we use ' $a$ ' and 'd' to denote an ascending and descending track, respectively.

To calculate geostrophic parameters of the LC (cf. Section 2.2), the absolute ocean dynamic heights are computed using the chosen equipotential (geoid) model on the same reference ellipsoid as used for the altimeter measurements. Hence, the accuracy of determination of an ocean current velocity depends mainly on the accuracy of the geoid model [cf. Eq. (3)]. We noted that an RMS of \pm 0.28 m exists on land when comparing AUSGeoid98 with newer GPS data across Australia (Featherstone and Sproule 2006). In this paper, the accuracy of the AUSGeoid98 model in the LC region is estimated by computing the standard deviation of a geoid slope along altimeter tracks for points separated by a known distance (cf. Rapp and Smith 1994). We computed the standard deviations of geoid slopes along six T/P tracks (a101, a177, a253, a075, d166, and d242) for points separated by $50-100 \mathrm{~km}$, the approximate known width of the LC. The RMS values are different from track to track due to the varying ship gravity observation distributions in the area.

From our computations, a standard deviation of the geoid slopes in the LC region was found to be about $1.5 \mathrm{ppm}$ (i.e., $15 \mathrm{~cm}$ in $100 \mathrm{~km}$ ). From Eq. (3), assuming no other error sources, the geoid slope error would result in a current velocity uncertainty of $19 \mathrm{~cm} \mathrm{~s}^{-1}$ at latitude $32^{\circ} \mathrm{S}$. This value is approximately $\sim 38 \%$ of the observed averaged surface geostrophic velocity and $\sim 19 \%$ of the maximum velocity seen in the LC region (Feng et al. 2005). This suggests that the AUSGeoid98 model may provide a useful basis for determining absolute surface current velocities in the LC region, but a filtering procedure is needed to reduce the geoid slope error (see section 3.1).

\subsection{Methods}

The along-track ocean dynamic height is used to compute the geostrophic parameters of interest, such as volume transport, axis velocity, height jump, width and axis locations of the current. Following Tai (1990), Rapp and Smith (1994) and Hwang (1996), the along-track dynamic height (SSH-geoid) across the LC front can be approximated by a hyperbolic function:

$S(x)=H \tanh \left(\frac{x-x_{0}}{L}\right)+S_{0}$

where $2 H$ is the height jump across the current, $x$ is the along-track distance increasing in the satellite flight direction, $x_{0}$ specifies the axis position of the current where the maximum geostrophic velocity occurs (cf. p. 6322 of Hwang 1996), $S_{0}$ is an unknown constant, and $L$ is a value related to the width of the current (p. 24709 of Rapp and Smith 1994):

$1.89 L=w / \cos \theta$

where $w / \cos \theta$ is the along-track width of the current, $w$ is the width of the current perpendicular to the along-current velocity, and $\theta$ is the angle between the cross-track velocity [Eq. (3)] and along-current geostrophic velocity (i.e., the direction of the current). Equation (2) implies that the velocity at the edge of the current decreases to about $50 \%$ of the maximum velocity of the LC. The four unknown parameters in Eq. (1), $H, x_{0}, L$, and $S_{0}$, are solved for by an iterative least-squares procedure (cf. Deng and Featherstone 2006).

Assuming geostrophic balance, the cross-track surface velocity, $v(x)$, of the LC can also be calculated from the along-track gradient $(\partial S / \partial x)$ of ocean dynamic heights as (e.g., Zlotnicki 1993; Morrow at al. 1994; Strub et al. 1997):

$v(x)=-\frac{g}{f} \frac{\partial S}{\partial x}=-\frac{g}{f} \frac{H}{L} \operatorname{sech}^{2}\left(\frac{x-x_{0}}{L}\right)$

where $g$ is the acceleration due to gravity and $f$ is the Coriolis parameter:

$f=2 \Omega \sin \phi$

where $\Omega=7.292115 \times 10^{-5} \mathrm{rads}^{-1}$ is the Earth's mean rotational velocity and $\phi$ is the geodetic latitude. The $v(x)$ is positive to the right of the track, when looking along the track from north to south in the Southern Hemisphere. Therefore all velocities and transports computed and discussed in section 3 will be negative.

The axis of the LC corresponds to the maximum crosstrack velocity (i.e., $x=x_{0}$ ), from which the axis is located at the centre of the current [Eq. (3)]. Thus, after solving for the parameters $H, L$, and $x_{0}$, the maximum cross-track velocity $v_{\max }$ can be estimated by Eq. (3), which can in turn be converted to the axis velocity $v\left(x_{0}\right)$ of the LC in the direction of the current through $v\left(x_{0}\right)=v_{\max } / \cos \theta$. 
To estimate the width $(w)$ of the current from Eq. (2), one has to know the value of angle $\theta$. From Fig. 2, ascending T/P tracks west of WA are not perpendicular to the direction of the LC, indicating $\theta \neq 0^{\circ}$. Since the LC flows along the continental shelf edge (e.g., Smith et al. 1991; Ridgway and Condie 2004), its direction appears to be approximately parallel to the satellite descending track in the region west of WA (cf. Fig. 1a of Feng et al. 2005). Thus, the angle $\theta$ between the cross-track velocity and direction of the LC west of WA can be approximately obtained by computing the angle between the cross-track velocity and directions of T/P's descending track at crossovers. Estimates of $\theta=43.45^{\circ}, 41.63^{\circ}$, and $39.68^{\circ}$ were found for tracks a 101 , a177, and a253, respectively. In the region south of WA, all tracks appear to be approximately perpendicular to the direction of the LC, suggesting estimates of $\theta=0^{\circ}$ can be assumed for all tracks in the region.

A two-layer ocean model (Tai 1990; Zlotnicki 1993) is employed here to estimate the baroclinic component (i.e., the volume transport) of the total ocean-mass transport. Another component of the total transport is the barotropic transport related to the lower layer. The model assumes that the bottom layer is at rest and that the volume transport is related only to the upper layer. It is acknowledged that this is not true for the LC due to the northwards undercurrent flowing beneath it. However, to a first-order approximation, the volume transport $\left(S_{c l}\right)$ of the upper layer can be estimated using the height jump $2 H$ as:

$S_{c l}=\frac{g}{f}(2 H) \eta$

where $\eta$ is the thickness of the top (upper) layer.

An accurate thickness of the top layer should be obtained from the surface to the depth of a certain temperature isotherm (cf. Tai 1990). An incorrect value of the layer thickness may result in under (or over) estimation of the transport. However, for comparison of results from all tracks in this study, we use a uniform layer thickness of $\eta=80 \mathrm{~m}$ as the average upper layer (mixed layer) for the LC. The value of $\eta$ is the same as that used by Smith et al. (1991).

\section{RESULTS AND DISCUSSION}

\subsection{Bimonthly Along-Track Ocean Dynamic Height along the $\mathrm{LC}$}

In order to observe the evolution of mean seasonal features of the LC during the period 1993 - 2002, and more importantly to obtain some initial values (e.g., axis location) for the geostrophic computation described in Section 2.2, we generated along-track bimonthly (60-day) averaged ocean dynamic heights and plotted them versus along-track latitude along the north-south extent of the $\mathrm{LC}$ in our region of interest (Figs. 3, 4, and 5). The time-period of 60 days was chosen to highlight the annual and seasonal variability character of the LC (cf. Feng et al. 2003).

The variations of bimonthly dynamic heights along three tracks a101, a177, and a253 versus along-track latitude are shown in Fig. 3. These tracks cross the LC at approximate latitudes of $26^{\circ} \mathrm{S}$ (a101), $29^{\circ} \mathrm{S}$ (a177), and $33^{\circ} \mathrm{S}$ (a253) over the continental shelf edge. Of the three tracks, a101 shows larger variations than tracks a177 and a253. The a101's maximum variation of $\sim 0.5 \mathrm{~m}$, which is related to the height jump of the LC along the track, occurs between March and April. Tracks a101 and a177 are affected by the no-data gaps editing when approaching the coastline meaning accurate assessment of geostrophic parameters close to the coastline may be problematic if the height profile is asymmetric.

Eddy-like features are observed in Fig. 3 around latitudes $\sim 32^{\circ} \mathrm{S}$ (a177), $35.5^{\circ} \mathrm{S}$ (a253), and $34^{\circ} \mathrm{S}$ (a253) during the period of 1993 - 2002. The existence of these eddies was also observed by Fang and Morrow (2003, Fig. 9) and Feng et al. (2005, Figs. 4, 5, and 6). Maximum dynamic heights of $\sim 0.3 \mathrm{~m}$ (a253) and $\sim 0.4 \mathrm{~m}$ (a177) occurred in late austral autumn (May - June) and winter (July - August), respectively, when the LC is at its strongest.

The along-track bimonthly averaged dynamic heights of the other nine tracks in the region south of WA are shown in Figs. 3 (a075), 4 (a151, a227, a049, a125), and 5 (d166, d242, d064, d140). The SSHs plotted along tracks a227 (Fig. 4), d064 (Fig. 5), and d140 (Fig. 5) exhibit only small dynamic height variations $(<0.2 \mathrm{~m})$. For tracks east of Cape Leeuwin and into the Great Australian Bight region (a075, a151, a227, a049, a125, d166, and d242), the along-track variations are also small over the region $\sim 37^{\circ} \mathrm{S}$ to $\sim 45^{\circ} \mathrm{S}$ $(<0.2 \mathrm{~m})$, as expected (Figs. 4, 5). The uniform changes in along-track dynamic height indicate that seasonal variations are small along most of these tracks during the period of 1993 - 2002.

Between latitudes $\sim 35^{\circ} \mathrm{S}$ and $\sim 38^{\circ} \mathrm{S}$, there is much more variation in the dynamic height profiles consistent with the presence of the eastward-flowing LC and their associated eddies (see for example, Cresswell and Griffin 2004, Figs. 2 and 13; Middleton and Platov 2003, Fig. 6). Tracks d166 and a151 give the same strong presence of the LC in their height profiles at their crossover point at $\sim 36.5^{\circ} \mathrm{S}$, giving confidence in our data analysis.

The LC and its eddy features were observed by Cresswell and Griffin (2004, Figs. 2 and 13), in which they investigated the formation and behaviour of eddies south of WA during 1994 using altimeter-derived SLAs and satelliteobserved sea-surface temperature imagery. Although these eddies formed and moved northward or westward in the area during 1994, Fig. 2 from Cresswell and Griffin (2004) shows that tracks a151, d166, and d242 always crossed the LC and its eddies at latitude $\sim 37^{\circ} \mathrm{S}$, while other tracks a227, 

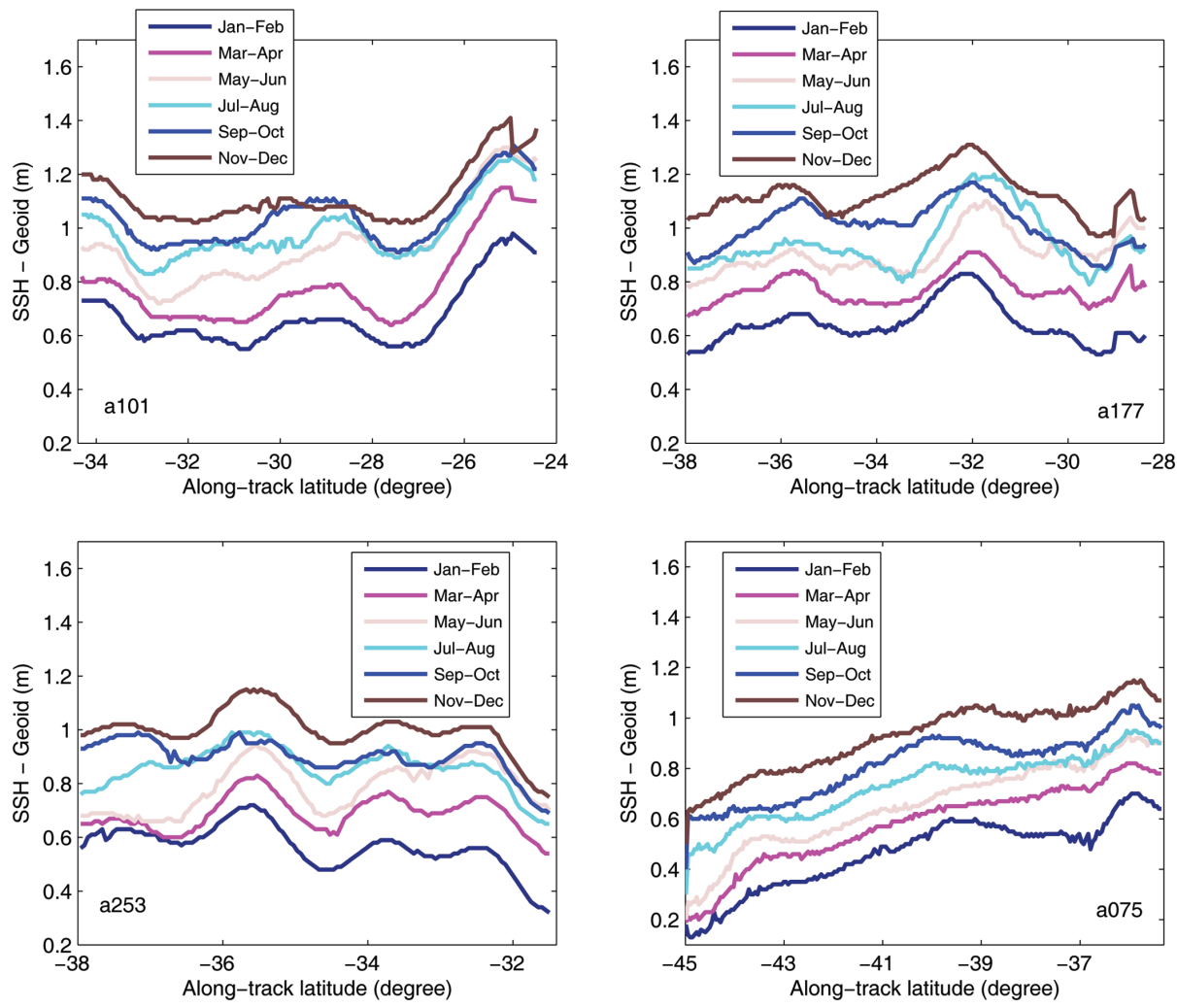

Fig. 3. Bimonthly averaged along-track ocean dynamic heights along four ascending tracks a101, a177, a253, and a075. Stacked plots are offset by $0.1 \mathrm{~m}$ with Jan-Feb values (the lowest curve) being true.
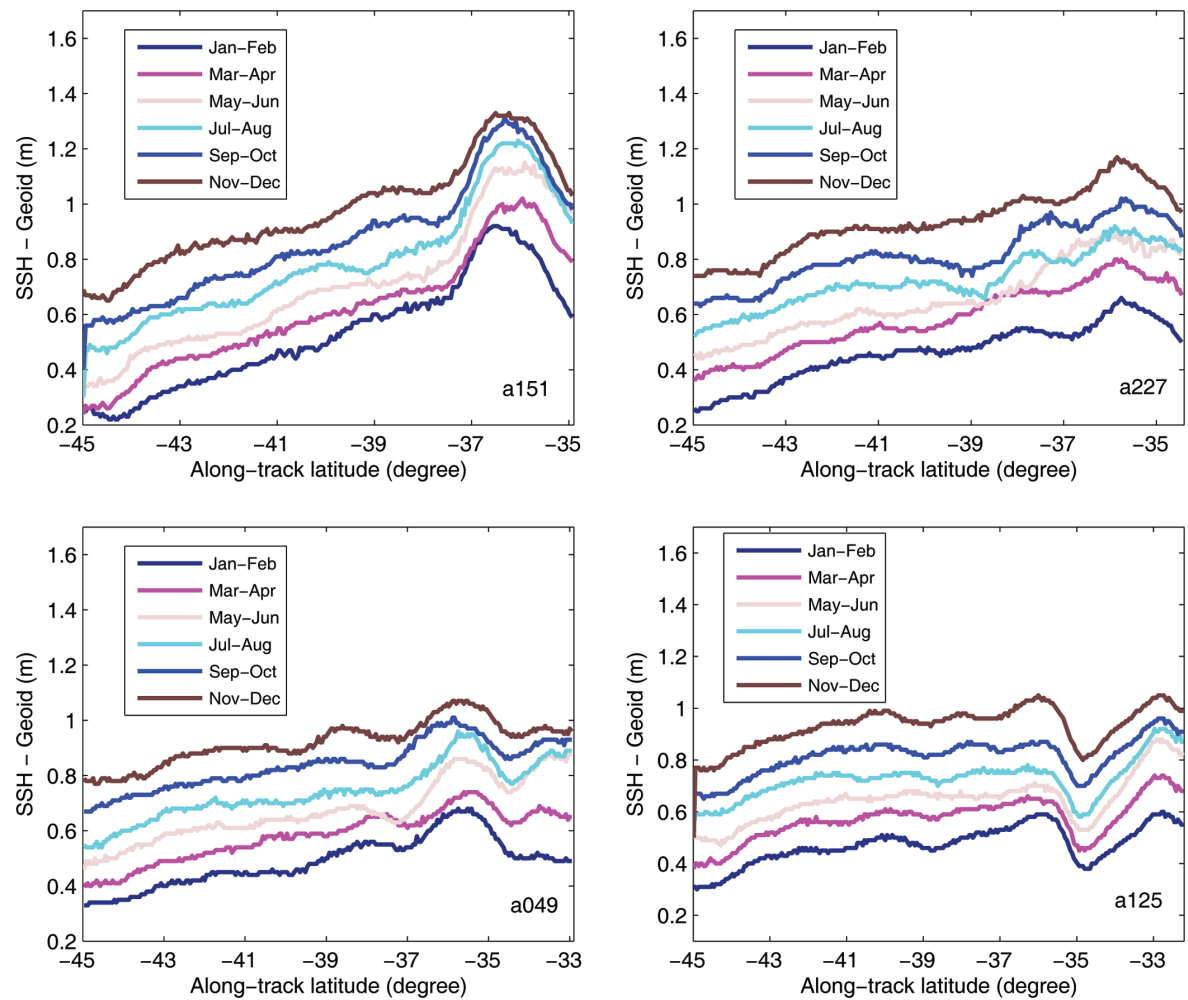

Fig. 4. Bimonthly averaged along-track ocean dynamic heights along four ascending tracks a151, a227, a049, and a125. Stacked plots are offset by $0.1 \mathrm{~m}$ with Jan-Feb values (the lowest curve) being true. 

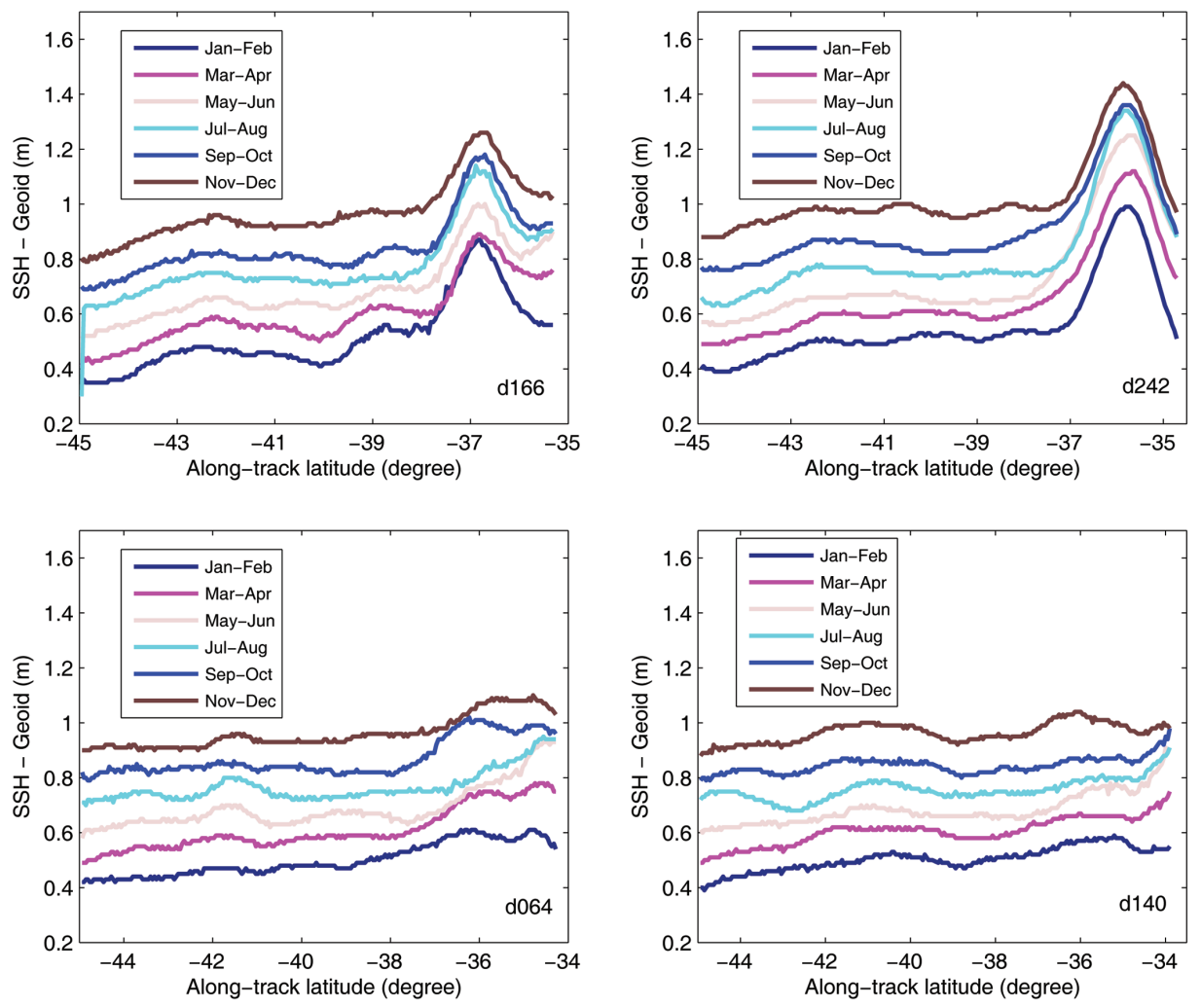

Fig. 5. Bimonthly averaged along-track ocean dynamic heights along four descending tracks d166, d242, d064, and d140. Stacked plots are offset by $0.1 \mathrm{~m}$ with Jan-Feb values (the lowest curve) being true.

a049, a125, d064, and d140 either crossed the edge of the eddy features or passed between the eddies.

The monthly positions of the migrating eddies A, B, and C from Cresswell and Griffin (2004, Fig. 13) are also drawn in Fig. 6, with good correlation with our estimated LC axis positions. When comparing these eddy positions with our bimonthly along-track ocean dynamic heights in Figs. 3, 4, and 5, we found consistent locations of eddy features at tracks a253 $\left(36.0^{\circ} \mathrm{S}\right)$, a151 $\left(36.1^{\circ} \mathrm{S}\right), \mathrm{d} 166\left(37.6^{\circ} \mathrm{S}\right)$, and $\mathrm{d} 242\left(37.1^{\circ} \mathrm{S}\right)$. Our study indicates that the absolute along-track dynamic heights computed from AUSGeoid98 and T/P SSHs can be used to observe the eddy characteristics of the LC.

From the analysis, along-track dynamic heights from eight ascending tracks show obvious variations over the continental shelf slope (Figs. 3, 4). They are chosen for the geostrophic parameter computations using the methods described in Section 2.2. The four descending tracks (Fig. 5) are not chosen because most of them failed to yield results in the model fitting procedure (cf. Section 2.2), due to the issues of assumed model function and its symmetry [see Eq. (1)]. Another way of looking at the issue is that the model fitting works for the north-south flowing LC, where it is clearly an eastern boundary current, but once the LC turns eastward around Cape Leeuwin, the dynamics of the flow change such that the model shape described by Eq. (1) is no longer valid.

\subsection{Geostrophic Parameters}

To reduce the noise caused partly by effects such as the geoid slope error, errors in geophysical corrections to the altimeter data and altimeter noise, a Gaussian filter [cf. Eq. (7) of Hwang and Kao 2002] is applied to ocean dynamic heights along the eight ascending tracks (Fig. 2) after calculating the along-track ocean dynamic height for each specific track. Since the size of the filter window directly affects the parameter estimates of the LC at track crossing points, an optimal window width of $50 \mathrm{~km}$ (using nine along-track points) was selected in this study. This was determined as optimal based upon the filter window widths suggested by Powell and Leben (2004). An iterative leastsquares fitting procedure (cf. Deng and Featherstone 2006) was used to solve for all unknown parameters, $H, x_{0}, L$, and $S_{0}$, in Eq. (1) and their error estimates for each cycle of the track. Other parameters $\left[w, v\left(x_{0}\right)\right.$, and $\left.S_{c l}\right]$ and their errors can subsequently be estimated based upon these solved parameters [cf. Eqs. (2), (3), and (5)]. 


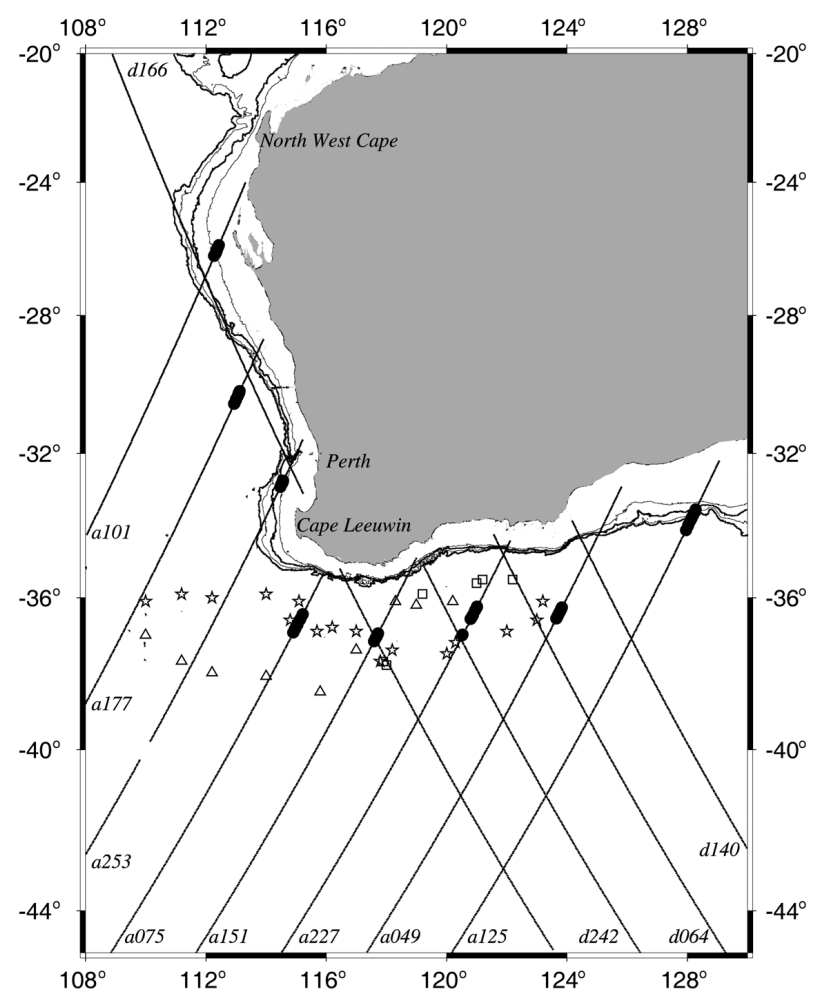

Fig. 6. Monthly averaged axis locations (highlighted by solid circles) of the LC at each T/P track in the region west and south of WA from January 1993 to August 2002. Symbols of triangle, star and square are approximately monthly positions of migrating (from east to west) eddies A, B, and C, respectively, from Cresswell and Griffin (2004, Fig. 13).

The smoothed data used in the fitting procedure were taken from $50 \mathrm{~km}$ each side of the estimated LC axis, unless inspection of the along-track ocean dynamic height profile indicated more or less data should be used. Some tracks were more asymmetric with respect to the LC axis $x_{0}$ than others. If the distance from the end of the track to $x_{0}$ is $<50 \mathrm{~km}$, it will affect the fit procedure when following the $50 \mathrm{~km}$ side-distance criterion. Therefore, the side-distance was reduced to $30-40 \mathrm{~km}$ depending on track geometry. The iterative procedure may not work in all cases, due partly to fewer data samples along track profiles closest to the coastline, or in some cases, partly to data noise and oceanic signal, such as eddies.

To help understand the time-invariant feature of the LC, the time-averaged estimates of the time-series of the LC geostrophic parameters and their RMS were computed (Table 1). It is acknowledged that the mean axis velocities and transports may not be adequate parameters to describe the features of the LC, as it is highly variable in terms of its seasonal flow and width. For example, from Table 1, all the time-series have relatively large RMS values, especially the width parameter, which may result from the presence of eddies and the LC's unique seasonal variability (cf. Cresswell and Griffin 2004; Ridgway and Condie 2004). However, the time-averaged parameters can still provide information about time-invariant current characteristics over the period 1993 to 2002.

From Table 1, assuming a mixed layer depth of $80 \mathrm{~m}$ for the volume transport parameter estimation for all tracks, the maximum mean transports are calculated as $-5 \pm 2.2 \mathrm{~Sv}$ $\left(10^{6} \mathrm{~m}^{3} \mathrm{~s}^{-1}\right)$ for track a101 in the region west of WA and $-7 \pm 2.5 \mathrm{~Sv}$ for track a151 in the region south of WA (cf. Fig. 2). The LC mean transports for tracks a101 and a177 are consistent with a steady flow and in agreement with the results of Feng et al. (2005, Fig 1b). Both transports and axis velocities from our results in Table 1 are higher than Feng et al. (2005)'s values by about $20 \%$; however, they use high-resolution upper ocean climatology and temperaturesalinity relationships to derive their results. Hence we are comparing in essence the quality of the geoid and the robustness of the model technique and its assumptions. Given these caveats, the results are encouraging.

The LC's mean transport is $-5 \pm 2.2 \mathrm{~Sv}$ when turning eastwards at track a075 $\left(\sim 115.0^{\circ} \mathrm{E} \sim-35.7^{\circ} \mathrm{S}\right)$, reaching a maximum of $-7 \pm 2.5 \mathrm{~Sv}$ at track a151 $\left(\sim 117.6^{\circ} \mathrm{E} \sim-37.1^{\circ} \mathrm{S}\right)$, and then maintains its strength at $\sim-4 \mathrm{~Sv}$ at tracks a227, a049, and a125. Middleton and Cirano (2002), Middleton and Platov (2003), and Cirano and Middleton (2004) show results of a high-resolution regional ocean model for the Great Australian Bight and Gulfs region of South Australia. In the domain of Fig. 2, it is difficult to exactly compare results. However, Middleton and Platov (2003) give a map of dynamic height (relative to the $2000 \mathrm{~m}$ isobath; their Fig. 6) that is in good agreement with the locations of the LC axis given in our Fig. 6. The agreement between the locations of the LC axis (Fig. 6) and mean surface steric height fields (relative to $2000 \mathrm{~m}$ ) based on the CSIRO's Atlas of Regional Seas (CARS) atlas (Fig. 2a of Ridgway et al. 2004) can also be observed south of WA. Comparison of our results with regional ocean model output is left for future work.

\subsection{Seasonal Variability}

To analyse the seasonal variation of the LC, the monthly mean values of $x_{0}, v\left(x_{0}\right), 2 H, S_{c l}$, and $w$ from January 1993 to July 2002 were calculated for the eight ascending tracks. The monthly mean of the LC's axis locations $\left(x_{0}\right)$ at each track is plotted in Fig. 6. Our results show the LC axis at tracks a101, a253, and a125 to be located above the continental shelf slope. Other LC axis locations are over the open ocean with average water depths $\sim 5000 \mathrm{~m}$ due partly to the lack of enough data coverage over the continental shelf slope. For example, track a177 crosses small islands when approaching the coastline around $\sim 29.5^{\circ} \mathrm{S}$ (cf. Fig. 2). The altimeter ranges are affected by the land topography, thus producing less valid altimeter SSHs (cf. Fig. 3 and Table 1). Therefore, the fitting procedure failed in the computation of 
Table 1. Means and RMS variabilities of the LC geostrophic parameters during 1993 - 2002.

\begin{tabular}{cccccccc}
\hline Track & $\begin{array}{c}\text { No of } \\
\text { cycles }\end{array}$ & $\begin{array}{c}\text { Transport } \\
(\mathbf{S v})\end{array}$ & $\begin{array}{c}\text { Axis velocity } \\
\left(\mathbf{c m ~ s}^{-1}\right)\end{array}$ & $\begin{array}{c}\text { Height jump } \\
(\mathbf{c m})\end{array}$ & Width $(\mathbf{k m})$ & $\begin{array}{c}\text { Mean } \\
\text { longitude of } \\
\text { axis }(\mathbf{d e g})\end{array}$ & $\begin{array}{c}\text { Mean latitude } \\
\text { of axis }(\mathbf{d e g})\end{array}$ \\
\hline a101 & 301 & $-5 \pm 2.2$ & $-41 \pm 10.5$ & $42 \pm 18.1$ & $105 \pm 35.0$ & $112.3 \pm 0.18$ & $-26.1 \pm 0.38$ \\
a177 & 170 & $-4 \pm 2.2$ & $-31 \pm 12.1$ & $19 \pm 11.0$ & $57 \pm 20.0$ & $113.0 \pm 0.26$ & $-30.4 \pm 0.48$ \\
a253 & 203 & $-2 \pm 1.3$ & $-21 \pm 8.8$ & $10 \pm 7.1$ & $42 \pm 15.0$ & $114.5 \pm 0.09$ & $-32.8 \pm 0.16$ \\
a075 & 170 & $-5 \pm 2.2$ & $-28 \pm 9.3$ & $29 \pm 13.4$ & $106 \pm 12.0$ & $115.1 \pm 0.30$ & $-36.7 \pm 0.47$ \\
a151 & 301 & $-7 \pm 2.5$ & $-41 \pm 12.6$ & $44 \pm 15.3$ & $110 \pm 22.8$ & $117.7 \pm 0.17$ & $-37.1 \pm 0.26$ \\
a227 & 219 & $-4 \pm 1.6$ & $-25 \pm 9.0$ & $24 \pm 9.2$ & $102 \pm 27.4$ & $120.9 \pm 0.32$ & $-36.5 \pm 0.51$ \\
a049 & 219 & $-4 \pm 1.8$ & $-21 \pm 9.4$ & $23 \pm 10.3$ & $112 \pm 26.5$ & $123.7 \pm 0.23$ & $-36.4 \pm 0.36$ \\
a125 & 259 & $-4 \pm 1.1$ & $-24 \pm 7.7$ & $25 \pm 9.6$ & $113 \pm 31.2$ & $128.2 \pm 0.31$ & $-33.8 \pm 0.54$ \\
\hline
\end{tabular}

the LC axis above the continental shelf slope for this track.

Figures 7,8, and 9 present the monthly means of $v\left(x_{0}\right)$, $2 H, S_{c l}$, and $w$ of the LC. Figure 7 shows the monthly means at three tracks a101, a177, and a253 west of WA. During every January - March between 1993 and 2003, when the LC is weak, the estimates of axis velocity $v\left(x_{0}\right)$ and volume transport $S_{c l}$ are relatively small (or weak) for three tracks (Figs. 7a, c), with lower height jumps $2 \mathrm{H}$ and narrow widths $w$ (Figs. 7b, d). The LC starts to strengthen from each March, consistent with other knowledge of the current (cf. Godfrey and Ridgway 1985; Feng et al. 2003; Cresswell and Griffin 2004).

The axis velocity $v\left(x_{0}\right)$ increases to maximum negative values (i.e., southward flowing) of 54,43 , and $28 \mathrm{~cm} \mathrm{~s}^{-1}$ in May and June at tracks a101, a177, and a253, respectively (Fig. 7a). For the same months, the corresponding volume transports reach peaks $(-7.2,-5.3$, and $-3.1 \mathrm{~Sv}$ in Fig. 7c), as well as height jump parameters $(59,27$, and $16 \mathrm{~cm}$ in Fig. 7b). The current width at a101 varies from $~ 90-100$ $\mathrm{km}$ during most months of the year. It starts to become wider in March and widest ( 132 km) in April, then becomes narrowest $(\sim 89 \mathrm{~km})$ in September (Fig. 7d). The LC is observed to be widest across profile a101 and about half the width $(50 \mathrm{~km})$ across the more southerly tracks a177 and a253, in agreement with sea surface temperature (SST) imagery and other knowledge of the LC (cf. Pearce 1991). The overall results for tracks a101 and a177 are consistent with Feng et al. (2005), as discussed above.

Figures 8 and 9 show the monthly means of parameters computed from five ascending tracks south of WA, where two tracks (a049 and a125) cross and three tracks (a075, a151, and a227) end at the edge of the continental shelf. Monthly mean estimates shown in Figs. 8 and 9 appear nosier than those in Fig. 7, but still show similar seasonal fea- tures as the tracks west of WA. The current width estimates are again nosier than other parameters for these tracks, suggesting that the geoid might not have adequate accuracy and/ or the model fitting procedure and its assumptions described in section 2.2 might not be valid for this region.

Table 2 lists the maximum and minimum estimates of the monthly mean of geostrophic volume transport, its standard deviation and the relevant months of the year for each track. The transport means have maximum values in winter between April and August, and minimum in summer between October and February for all tracks, which agrees well with previous oceanographic research (e.g., Smith et al. 1991; Griffin et al. 2001; Feng et al. 2003). The highest maximum transport of the LC is $-8.4 \mathrm{~Sv}$ in August across track a151 near Cape Leeuwin, a location where the LC starts to change its flow direction from meridional to zonal. The second highest maximum volume transport (-7.2 Sv in April) is found at the location across track a101 west of WA. The lowest minimum volume transport of the LC is $-0.8 \mathrm{~Sv}$ in December and January across a253 near Fremantle to the west of WA and a125 in the region to the south of WA.

Feng et al. (2003) show the monthly mean geostrophic volume transport (from 1950 to 2000) referenced to a $300 \mathrm{~m}$ water depth east of $110^{\circ} \mathrm{E}$ along $32^{\circ} \mathrm{S}$, a location close to the LC's axis at the T/P track a253 (Fig. 6). Their results (top figure in Fig. 8 of Feng et al. 2003) indicate that the monthly transport has a maximum in June $(\sim-5 \mathrm{~Sv})$ and minimum in January $(\sim-2.2 \mathrm{~Sv})$. Our maximum $(-3.1 \mathrm{~Sv})$ and minimum $(-0.8 \mathrm{~Sv})$ values of monthly mean transports listed in Table 2 for track a253 are smaller than those from Feng et al. (2003) because of different ocean depths used when computing the transport ( $300 \mathrm{~m}$ versus our $80 \mathrm{~m}$ ). The bias of about $2 \mathrm{~Sv}$ between results is explainable by this reference surface difference. However, the monthly mean 
(a)

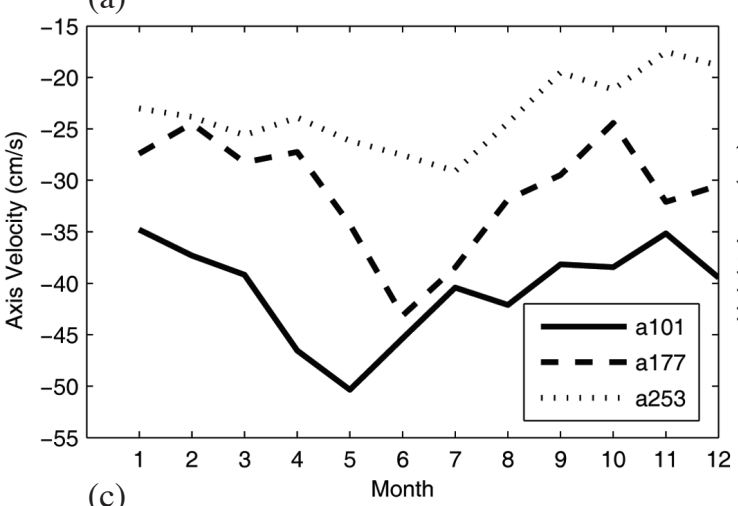

(c)

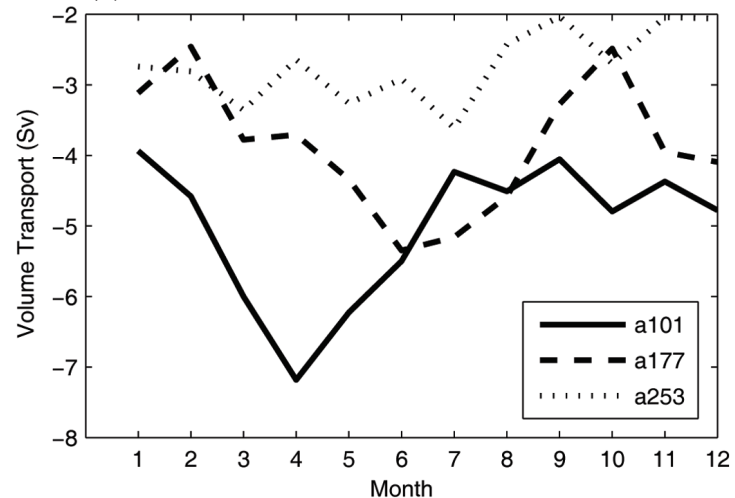

(b)

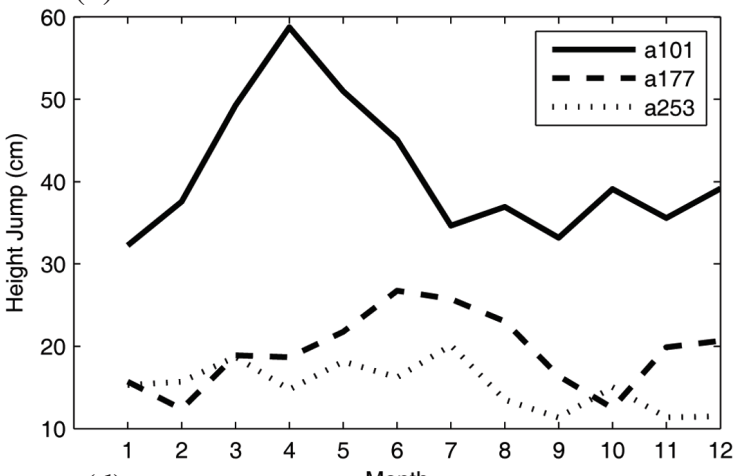

(d)

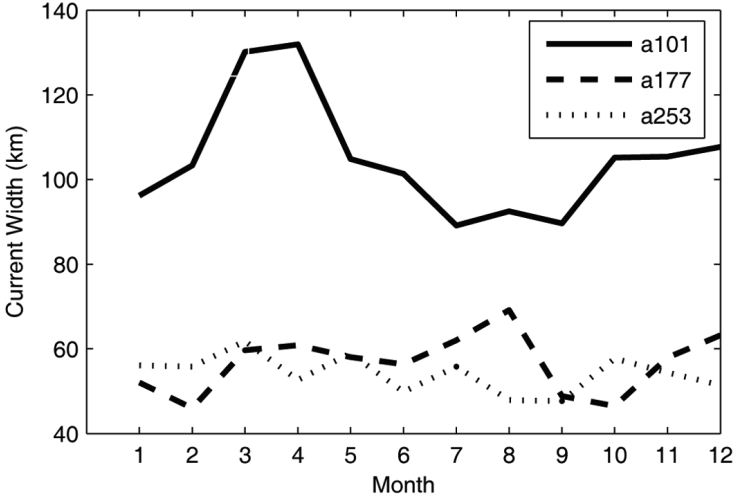

Fig. 7. Monthly averaged axis velocity (a), height jump (b), geostrophic volume transport (c), and width (d) of the LC from January 1993 to August 2002 for three tracks a101, a177, and a253. Negative velocities (a) indicate that they are left of the track, when looking along the track from north to south. Negative transports (c) mean the current is southward and $1 \mathrm{~Sv}=10^{6} \mathrm{~m}^{3} \mathrm{~s}^{-1}$.

(a)

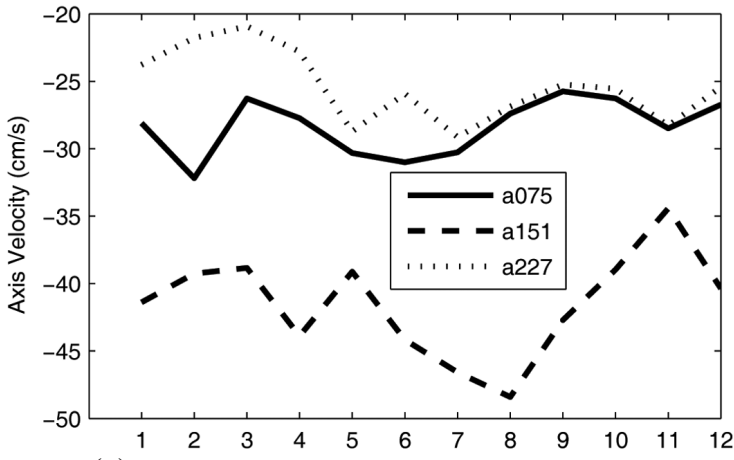

(c)

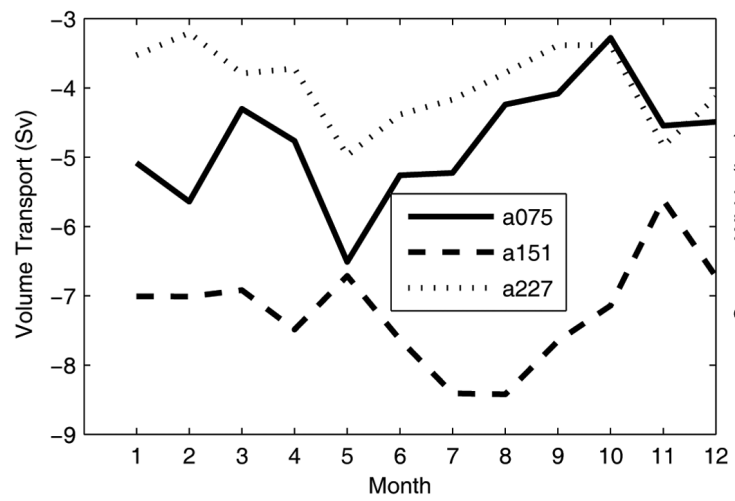

(b)

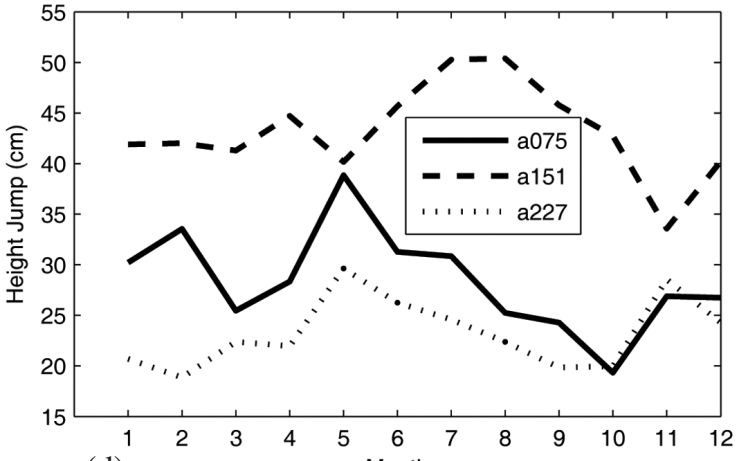

(d)

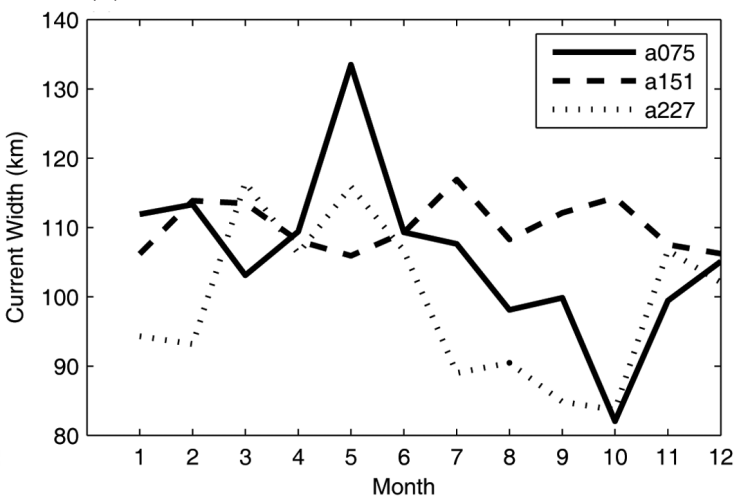

Fig. 8. Monthly averaged axis velocity (a), height jump (b), geostrophic volume transport (c), and width (d) of the LC from January 1993 to August 2002 for three tracks a075, a151, and a227. Negative velocities (a) indicate that they are left of the track, when looking along the track from north to south. Negative transports (c) mean the current is southward and $1 \mathrm{~Sv}=10^{6} \mathrm{~m}^{3} \mathrm{~s}^{-1}$. 
(a)

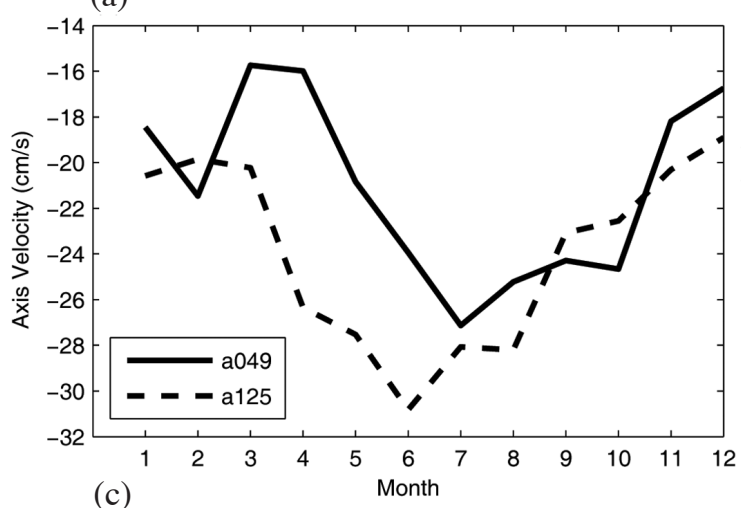

(c)

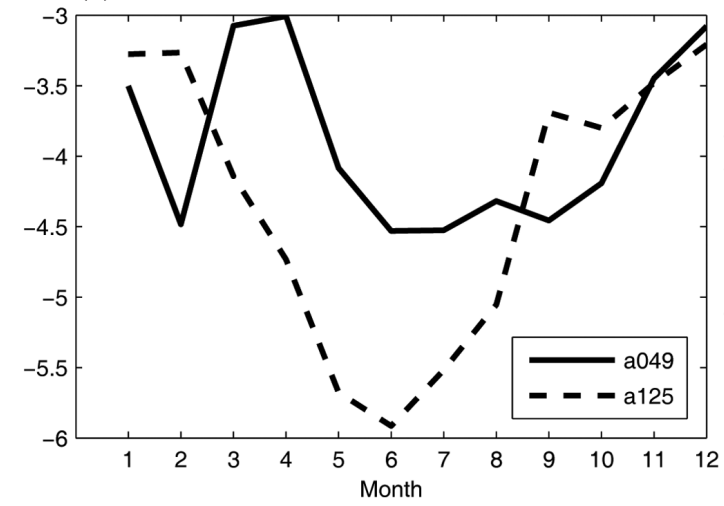

(b)

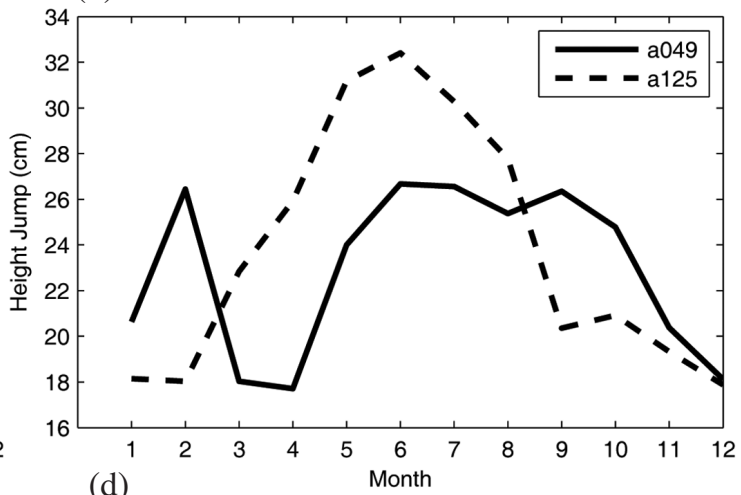

(d)

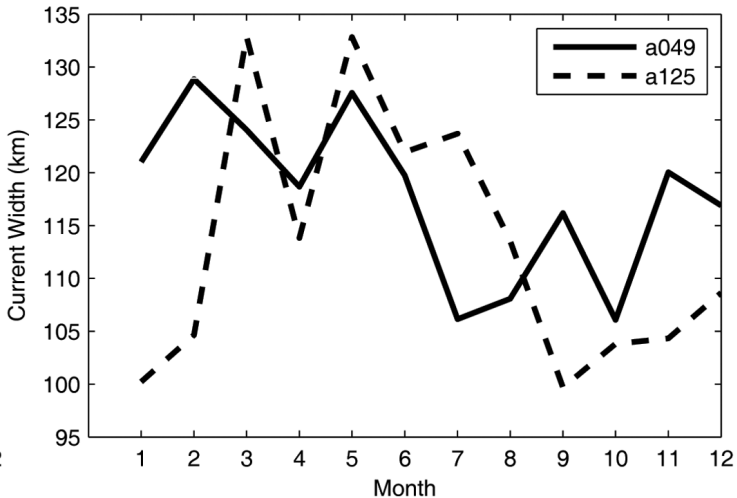

Fig. 9. Monthly averaged axis velocity (a), height jump (b), geostrophic volume transport (c), and width (d) of the LC from January 1993 to August 2002 for three tracks a049, and a125. Negative velocities (a) indicate that they are left of the track, when looking along the track from north to south. Negative transports (c) mean the current is southward and $1 \mathrm{~Sv}=10^{6} \mathrm{~m}^{3} \mathrm{~s}^{-1}$.

Table 2. Maximum and minimum monthly means of volume transports $\left(S_{c l}\right)$, their standard deviation (STD) and time when $S_{c l}$ reaches these values along each altimeter track.

\begin{tabular}{ccccccc}
\hline Track & Max $(\mathbf{S v})$ & STD $(\mathbf{S v})$ & Time of $\mathbf{m a x}$ & Min $(\mathbf{S v})$ & STD $(\mathbf{S v})$ & Time of min \\
\hline a101 & -7.2 & 2.4 & Apr & -1.5 & 3.9 & Jan \\
a177 & -5.4 & 2.7 & Jun & -1.2 & 2.5 & Oct \\
a253 & -3.1 & 2.0 & Jun & -0.8 & 1.2 & Jan \\
a075 & -6.5 & 2.4 & May & -1.4 & 3.3 & Oct \\
a151 & -8.4 & 2.0 & Aug & -1.7 & 5.6 & Nov \\
a227 & -5.0 & 2.3 & May & -1.0 & 3.2 & Feb \\
a049 & -4.5 & 1.5 & Jun & -1.1 & 3.1 & Dec \\
a125 & -5.9 & 2.2 & Jun & -0.8 & 3.2 & Dec \\
\hline
\end{tabular}

transports at track a253 from Table 2 reach a maximum in June and minimum in January, which agrees well with Feng et al. (2003).

\subsection{Interannual Variability}

ENSO is a coupled ocean-atmosphere phenomena that has a worldwide impact on climate on interannual time scales. NINO3 is an index that measures the strength of an ENSO event using SST anomalies averaged over the eastern equatorial Pacific $\left(5^{\circ} \mathrm{S}<\phi<5^{\circ} \mathrm{N}, 180^{\circ} \mathrm{W}<\lambda<90^{\circ} \mathrm{W}\right)$. On the basis of the NINO3 SST index and the geostrophic volume transport, the possible relationship between the interannual variability of the LC and ENSO is investigated next. 
In order to compare NINO3 index with volume transport estimates from this study, the normalised values (defined as $(x-\bar{x}) / \sigma_{x}$, where $x$ is the NINO3 SST-index or geostrophic transport) of NINO3 SST anomalies and geostrophic transports are computed for the eight ascending $\mathrm{T} / \mathrm{P}$ tracks. These normalised values are then filtered using a low-pass Gaussian filter with a 12-month window. The window size was chosen based on the annual cycle obtained from Section 3.3. The filtered values are plotted versus time in Figs. 10, 11, and 12, where a negative sign has been applied to normalised volume transports so that they have a sign consistent with the NINO3 SST.

During the 1993 - 2003 period of T/P data analysed in this paper, there were three El Niño events in 1993 - 1994, 1994 - 1995, and 1997 - 1998, and four La Niña events in 1995 - 1996, 1998 - 1999, 1999 - 2000, and 2000 - 2001. During an El Niño year, NINO3 SST anomalies start to increase early in the austral winter and reach their maximum in the austral summer (November - December). Conversely, during a La Niña year, the NINO3 SST anomaly has minimum values during these months. El Niño years have higher NINO3 SST anomalies than normal, while La Niña years have the opposite (Fig. 10).

Figure 10 shows normalised NINO3 SST anomalies and volume transport estimates for tracks a101, a177, and a253. The normalised transport values at track a101 were not affected by ENSO events in 1993 - 1994, 1994 - 1995, and 1995 - 1996. Both NINO3 SST anomalies and transports have the maximum and minimum at similar months during these years. However, the effect of the 1997 - 1998 El Niño event is seen as a suppression of the seasonal minimum of the transport, and this happens also in $2002-2003$ at the end of the data series. El Niño events seem to affect the volume transports at tracks a177 and a253 more than those at a101 during 1993 - 1994 and 1994 - 1995.

The normalised transport at track a177 has a minimum in November 1994, a time when the NINO3 SST anomalies had the maximum in an El Niño year 1994 - 1995. Normalised transports along a253 were lower than normal in 1993 - 1994 and had opposite maxima to NINO3 SST anomalies in 1994 - 1995. The largest El Niño event occurred in year 1997 - 1998 and had much higher NINO3 SST anomalies than normal, while normalised volume transports were lower than normal for all tracks. Conversely, La Niña years of 1998 - 1999, 1999 - 2000, and 2000 - 2001 show higher transports and lower NINO3 SST anomalies than normal at these three tracks.

Figures 11 and 12 show normalised volume transports and NINO3 SST anomalies at five tracks south of WA. Most La Niña years have higher volume transports than normal, while most El Niño years have lower geostrophic transports than normal. All these distinct values of normalised volume transports occurred during the periods of El Niño and La Niña events might be an indication of the interannual

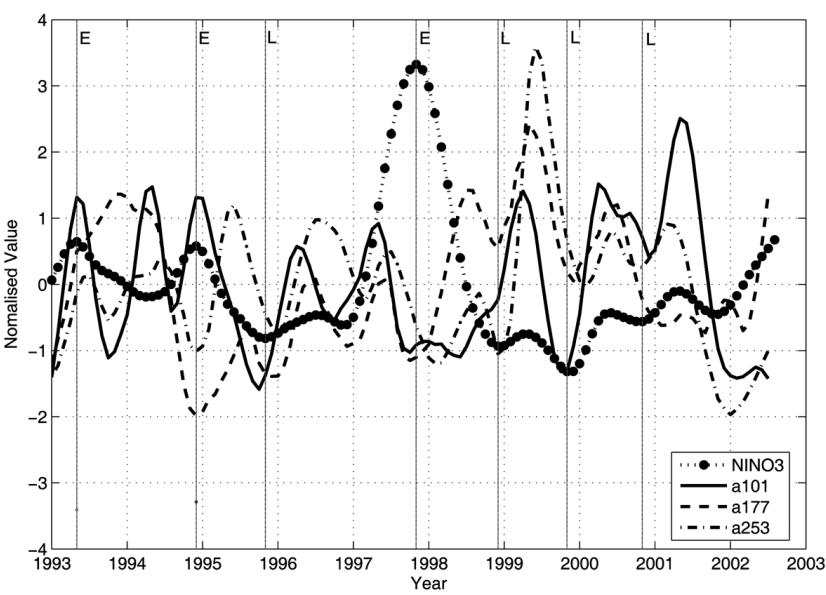

Fig. 10. Normalised time-series of NINO3 SST anomalies and geostrophic volume transports for tracks a101, a177, and a253. Vertical solid lines indicate the year of ENSO events, from which "E" and "L" mark the peaks of El Niño and La Niña years, respectively.

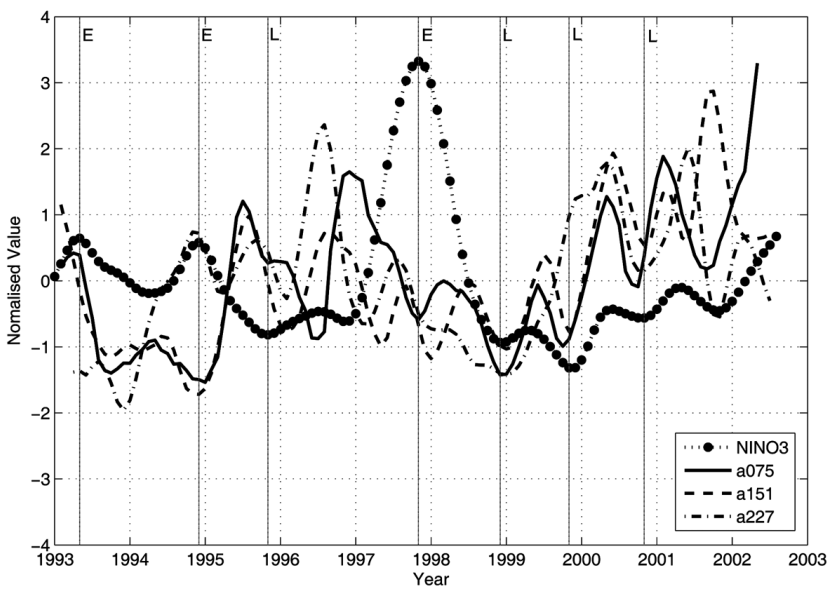

Fig. 11. Normalised time-series of NINO3 SST anomalies and geostrophic volume transports for tracks a075, a151, and a227. Vertical solid lines indicate the year of ENSO events, from which "E" and "L" mark the peaks of El Niño and La Niña years, respectively.

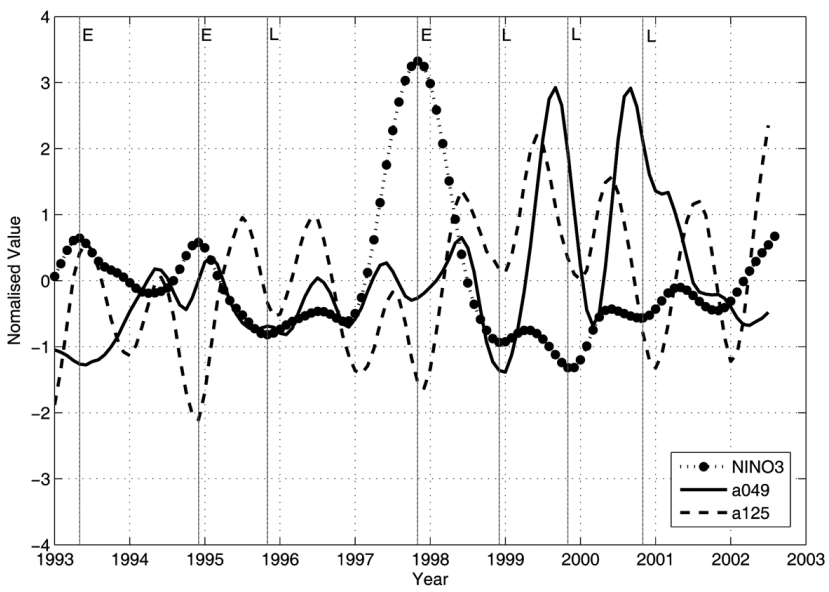

Fig. 12. Normalised time-series of NINO3 SST anomalies and geostrophic volume transports for tracks a049, and a125. Vertical solid lines indicate the year of ENSO events, from which "E" and "L" mark the peaks of El Niño and La Niña years, respectively. 
variations of the $\mathrm{LC}$. The results here suggest that the $\mathrm{LC}$ is stronger in most La Niña years and weaker in most El Niño years in regions both west and south of WA. This result also agrees with Feng et al. (2003).

We also computed the cross-correlations at different time lags between the LC's transport parameter and the NINO3 SST index. Table 3 lists the maximum correlation coefficients and corresponding lags for the T/P tracks. From Table 3, the correlations with the NINO3 SST index are $-0.44,0.55$, and -0.49 in the region west of WA for tracks a101, a177, and a253, respectively. Tracks located south of WA show more statistically significant correlations from -0.45 to -0.70 with the NINO3 SST index than those west of WA, except for track a049 (-0.36). All correlations are negative, except for track a177 (Table 3), indicating that two phases of the volume transport and NINO3 SST index are reversed at the lag of maximum correlation. When considering the magnitude of correlation coefficients and the uncertainties in volume transports (Figs. 10, 11, and 12), we conclude that most tracks do have statistical correlation with the NINO3 SST index.

One problem from the cross-correlation computations described in this section is the relatively large time-lag difference between some adjacent tracks. For example, tracks a049 and a125 have correlations with the NINO3 SST index at time lags of -10 and 4 months, respectively (Table 3). This large difference might result from data noise from the combined impact of errors in AUSGeoid98 and geophysical corrections applied to T/P altimeter SSHs.

\section{CONCLUSIONS AND RECOMMENDATIONS}

The seasonal and interannual features of the LC have been, for the first time to our knowledge, analysed using nearly 9.5-years of T/P-derived SSHs and AUSGeoid98 geoid heights. The time-series of geostrophic parameters of the volume transport, axis velocity, axis location, width and height jump of the LC in the regions to west and south of WA have been computed from the along-track ocean dynamic heights.

Eddies are observed in the LC region, in particular to the south of WA, from bimonthly (60-day) averaged alongtrack ocean dynamic heights. Along-track ocean dynamic heights from two descending tracks $\mathrm{d} 166$ and $\mathrm{d} 242$ consistently show obvious variations $(\sim 0.4 \mathrm{~m}$ for $\mathrm{d} 166$ and $\sim 0.6 \mathrm{~m}$ for $\mathrm{d} 242$ ) at latitudes between $\sim 35^{\circ} \mathrm{S}$ and $\sim 37.5^{\circ} \mathrm{S}$ during the period of 1993 - 2002. This suggests that ocean dynamic heights computed from AUSGeoid 98 and T/P altimeter data have the potential to measure the eddy field in coastal regions.

The mean geostrophic transports of the LC west of WA are in reasonable agreement with oceanographic results by Feng et al. (2003, 2005). When the LC flows eastward into the region of south of WA, the mean transport values
Table 3. Maximum cross-correlations and lags between the $\mathrm{LC}$ volume transports $\left(S_{c l}\right)$ and NINO3 SST index.

\begin{tabular}{ccc}
\hline Tracks & Maximum correlation & Lag* (month) \\
\hline a101 & $-0.44 \pm 0.23$ & -6 \\
a177 & $0.55 \pm 0.24$ & -16 \\
a253 & $-0.49 \pm 0.22$ & -4 \\
a075 & $-0.61 \pm 0.20$ & -15 \\
a151 & $-0.45 \pm 0.23$ & -14 \\
a227 & $-0.64 \pm 0.22$ & -10 \\
a049 & $-0.36 \pm 0.24$ & -10 \\
a125 & $-0.70 \pm 0.15$ & 4
\end{tabular}

* A positive time lag means that the NINO3 SST leads the transport, and vice versa.

increase to $-5 \pm 2.2 \mathrm{~Sv}$ for track a075 $\left(115.0^{\circ} \mathrm{E}, 36.7^{\circ} \mathrm{S}\right)$ and reach the most maximum $-7 \pm 2.5 \mathrm{~Sv}$ for track a151 $\left(117.6^{\circ} \mathrm{E}, 37.1^{\circ} \mathrm{S}\right)$, with the location of the $\mathrm{LC}$ axis in good agreement with climatology results (Ridgway et al. 2004; Middleton and Platov 2003).

The LC is highly variable in terms of its geostrophic parameters at seasonal and annual time-scales in different coastal regions. On the seasonal time-scale, the LC is weak ( -0.8 to $-1.7 \mathrm{~Sv}$ ) between October and February during the austral summer and strong (-3.1 to $-8.4 \mathrm{~Sv}$ ) between April and August during the austral winter. On the interannual time-scale, the LC is stronger with higher normalised transport values than normal (i.e., the average transport during 1993 - 2003) in a La Niña year and weaker with lower normalised transports than normal in an El Niño year when using NINO3 SST anomalies as an ENSO index. These observations are consistent with the work of Feng et al. (2005).

Results here have demonstrated that boundary current systems, such as the LC, which are relatively narrow in width and within the coastal slope region, can be studied using altimeter-derived absolute SSH data in combination with a local gravimetric geoid model. However, further study is necessary to decrease (or at least retain) the present formal error levels of the geoid models and at the same time reduce the true errors of these models.

This paper has also raised some challenging questions. For example, how accurate and what resolution should a regional gravimetric model be in the LC region? How could we accurately compute the absolute current in coastal regions? How could we improve altimeter data and reduce the "no-data gap" issue near coastlines? To better monitor ocean boundary currents, it is essential that we solve these questions.

The slope error in the existing AUSGeoid98 model is 
$\sim 1.5 \mathrm{ppm}$ in the LC region, which should be improved for the applications of estimating the absolute current from the combination of a regional geoid with altimetry. With the advent of new data from dedicated satellite gravity missions, such as GRACE and GOCE, the global geoid models will significantly improve over smaller length scales. The improvement of the local geoid model will, however, depend largely on having additional in-situ gravity measurements and the methods used to combine them. The coastal ocean is poorly observed by the present generation of radar altimeters since they cannot measure the sea surface close to shore. Altimeter data quality can be improved using waveform retracking algorithms (e.g., Deng and Featherstone 2006), and by applying improved geophysical and environmental corrections, especially the ocean tide and wet tropospheric corrections (e.g., Fernandes et al. 2006).

Another challenge is the further investigation of the relationship between the interannual variability of LC and ENSO events. While the above three questions are recently becoming more solvable, there is still significant research to be made in cross-correlation analysis for a better understanding of how the LC responds to a changing climate in Australia.

Acknowledgements Dr. Xiaoli Deng is supported by University of Newcastle Research grants, Australia. Prof. Will Featherstone is funded by Australian Research Council (ARC) grant DP0663020. We would like to thank Dr. David Griffin and Dr. Ken Ridgway (CSIRO Marine and Atmospheric Research, Australia) for kindly providing the oceanic in-situ data and Prof. Mark Stewart (The University of Newcastle) for useful comments. We also gratefully acknowledge useful suggestions from the editor and anonymous reviewers.

\section{REFERENCES}

AVISO/Altimetry, 1996: AVISO User Handbook for Merged TOPEX/POSEIDON products, AVI-NT-02-101, Edition 3.0.

Brooks, R. L., D. W. Lockwood, and J. E. Lee, 1997: Land effects on TOPEX radar altimeter measurements on Pacific Rim coastal zones. NASA WFF publ., http:// topex.wff.nasa.gov/.

Cirano, M., and J. F. Middleton, 2004: Aspects of the mean wintertime circulation along Australia's southern shelves: Numerical studies. J. Phys. Oceanogr., 34, 668-684.

Clarke, A. J., and X. Liu, 1994: Interannual sea level in the northern and eastern Indian Ocean. J. Phys. Oceanogr., 24, 1224-1235.

Cresswell, G. R., 1991: The Leeuwin Current - observations and recent models. J. Royal Soc. Western Australia, 74, 1-14.
Cresswell, G. R., and D. A. Griffin, 2004: The Leeuwin Current eddies, and sub-Antarctic waters off southwest Australia. Mar. Freshwater Res., 55, 267-276.

Deng, X., and W. E. Featherstone, 2006: A coastal retracking system for satellite radar altimeter waveforms: Application to ERS-2 around Australia. J. Geophys. Res., 111, C06012, doi: 10.1029/2005JC003039.

Domingues, C. M., S. E. Wijffels, M. E. Maltrud, J. A. Church, and M. Tomczak, 2006: Role of eddies in cooling the Leeuwin Current. Geophys. Res. Lett., 33, L05603, doi: 10.1029/2005GL025216.

Eanes, R., and S. Bettadpur, 1995: The CSR 3.0 global ocean tide model, Center for Space Research, University of Texas, Austin, TX.

Fang, F., and R. Morrow, 2003: Evolution, movement and decay of warm-core Leeuwin Current eddies. DeepSea Res. II, 50, 2245-2261.

Featherstone, W. E., J. F. Kirby, A. H. W. Kearsley, J. R. Gilliland, G. M. Johnston, J. Steed, R. Forsberg, and M. G. Sideris, 2001: The AUSGeoid98 geoid model of Australia: Data treatment, computations and comparisons with GPS-levelling data. J. Geod., 75, 313-330, doi: $10.1007 / \mathrm{s} 001900100177$.

Featherstone, W. E., and D. M. Sproule, 2006: Fitting AUSGeoid98 to the Australian Height Datum using GPS data and least squares collocation: Application of a cross-validation technique. Surv. Rev., 38, 573-582.

Feng, M., G. Meyers, A. Pearce, and S. Wijffels, 2003: Annual and Interannual variations of the Leeuwin Current at $32^{\circ}$ S. J. Geophy. Res., 108, 19.1-19.21.

Feng, M., S. Wijffels, S. Godfrey, and G. Meyers, 2005: Do eddies play a role in the momentum balance of the Leeuwin Current? J. Phys. Oceanogr., 35, 964-975.

Fernandes, M. J., S. Barbosa, and C. Lázaro, 2006: Impact of altimeter data processing on sea level studies. In: Chen, G., and G. D. Quartly (Eds.), Special Issue on "Satellite Altimetry: New Sensors and New Application", Sensors, 6, 131-163.

Godfrey, J. S., and K. R. Ridgway, 1985: The large-scale environment of the poleward-flowing Leeuwin Current, Western Australia: Longshore steric height gradients, wind stresses and geostrophic flow. J. Phys. Oceanogr., 15, 481-495.

Griffin, D. A., L. W. John, C. F. Chris, P. F. Alan, and C. Nick, 2001: Ocean currents and the larval phase of Australian western rock lobster, Panulirus Cygnus. Mar. Freshwater Res., 52, 1187-1199.

Haines, K., R. Hipkin, C. Beggan, R. Bingley, F. Hernandez, J. Holt, T. Baker, and R. J. Bingham, 2003: Combined use of altimetry and in situ gravity data for coastal dynamics Studies. Space Sci. Rev., 108, 205-216.

Hwang, C., 1996: A Study of the Kuroshio's seasonal variabilities using an altimetric-gravimetric geoid and TOPEX/POSEIDON altimeter data. J. Geophy. Res., 
101, 6313-6335.

Hwang, C., and R. Kao, 2002: TOPEX/POSEIDON-derived space-time variations of the Kuroshio Current: Applications of a gravimetric geoid and wavelet analysis. Geophys. J. Int., 151, 835-847.

Le Traon, P. Y., and R. Morrow, 2001: Ocean currents and eddies. In: Fu, L. L., and A. Cazenave (Eds.), Satellite Altimetry and Earth Sciences: A Handbook of Techniques and Applications, Academic Press, San Diego, 171-216.

LeGrand, P., 2005: Future gravity missions and quasisteady ocean circulation. Earth, Moon, and Planets, 94, 57-71, doi: 10.1007/s11038-004-7606-9.

Middleton, J. F., and M. Cirano, 2002: A northern boundary current along Australia's southern shelves: The Flinders Current. J. Geophys. Res., 107, doi: 10.1029/ 2001JC000701.

Middleton, J. F., and G. Platov, 2003: The mean summertime circulation along Australia's southern shelves: A numerical study. J. Phys. Oceanogr., 33, 2270-2287.

Morrow, R., R. Coleman, J. Church, and D. Chelton, 1994: Surface eddy momentum flux and velocity in the Southern Ocean from Geosat altimetry. J. Phys. Oceanogr., 24, 2050-2071.

Morrow, R., and F. Birol, 1998: Variability in the Southeast Indian Ocean from altimetry: Forcing mechanisms for the Leeuwin Current. J. Geophy. Res., 103, 1852918544.

Morrow, R., F. Fang, M. Fieux, and R. Molcard, 2003: Anatomy of three warm-core Leeuwin Current eddies. Deep-Sea Res., 50, 2229-2243.

Pariwono, J. I., J. A. T. Bye, and G. W. Lennon, 1986: Long-period variations of sea level in Australasia. Geophys. J. R. Astron. Soc., 87, 43-54.

Pearce, A. F., 1991: Eastern Boundary Currents of the Southern Hemisphere. J. Royal Soc. Western Australia, 74, 35-45.

Powell, B., and R. Leben, 2004: An optimal filter for geostrophic mesoscale currents from along-track satellite altimetry. J. Atmos. Ocean. Tech., 21, 1633-1642.
Rapp, R. H., and D. A. Smith, 1994: Preliminary estimates of Gulf Stream characteristics from TOPEX Data and A Precise Gravimetric Geoid. J. Geophy. Res., 99, $24707-$ 24723.

Ridgway, K. R., and S. A. Condie, 2004: The 5500-km-long boundary flow off western and southern Australia. $J$. Geophy. Res., 109, C04017, doi: 10.1029/2003JC001921.

Smith, R. L., A. Huyer, J. S. Godfrey, and J. A. Church, 1991: The Leeuwin Current off Western Australia, 1986 - 1987. J. Phys. Oceanogr., 21, 323-345.

Strub, P. T., T. K. Chereskin, P. P. Niiler, C. James, and D. M. Levine, 1997: Altimeter-derived variability of surface velocity in the California Current system, 1. Evaluation of TOPEX altimeter velocity resolution. $J$. Geophy. Res., 102, 12727-12748.

Tai, C. K., 1990: Estimating the surface transport of meandering oceanic jet streams from satellite altimetry: Surface transport estimates for the Gulf Stream and Kuroshio extension. J. Phys. Oceanogr., 20, 860-879.

Tapley, B. D., D. P. Chambers, S. Bettadpur, and J. C. Ries, 2003: Large-scale ocean circulation from the GRACE GGM01 geoid. Geophys. Res. Lett., 30, doi: 10.1029/ 2003GL018622

Tapley, B. D., S. Bettadpur, M. Watkins, and C. Reigber, 2004: The gravity recovery and climate experiment: Mission overview and early results. Geophys. Res. Lett., 31, L09607, doi: 10.1029/2004GL019920.

Thompson, R. O. R. Y., 1984: Observations of the Leeuwin Current off Western Australia. J. Phys. Oceanogr., 14, 623-628.

Wang, Y. M., and R. H. Rapp, 1991: Geoid gradients for Geosat and Topex/Poseidon repeat ground tracks, 408, The Ohio State University, Columbus, USA, 26 pp.

Wijffels, S., and G. Meyers, 2004: An intersection of oceanic waveguides: Variability in the Indonesian throughflow region. J. Phys. Oceanogr., 34, 1232-1253.

Zlotnicki, V., 1993: Quantifying time-varying oceanographic signals with altimetry. In: Rummel, R., and F. Sanso (Eds.), Satellite Altimetry in Geodesy and Oceanography, Lecture Notes in Earth Sciences, 50, 143-188. 